\title{
UNIVERSOS ÉTICOS Y LA METARREGLA DEL DOBLE EFECTO EN EL ESTADO DE NECESIDAD*
}

\section{ETHICAL UNIVERSES AND THE META-RULE OF DOUBLE EFFECT IN STATE OF NECESSITY}

\author{
Raúl MADRID RAMÍREZ ${ }^{* *}$ \\ Rodrigo Andrés GUERRA ESPINOSA ${ }^{* * *}$
}

\section{Resumen:}

Este artículo tiene por objeto explicar cuándo en el estado de necesidad la distinción entre un mal mayor o menor responde al universo ético consecuencialista y desde qué consideraciones no lo haría; segundo, explicar por qué es posible desde el principio del doble efecto la ponderación de la vida humana, aceptando la objetivización de sus parámetros según los efectos de una acción. Por ello, a continuación trataremos en la primera sección el concepto de mal en clave consecuencialista y, posteriormente, moral absolutista. Se trata de un análisis sobre la materia que reconoce, en la segunda sección, la importancia de la existencia de estos universos en la ponderación de males. Luego, contrastaremos nuestros razonamientos con las soluciones que, para casos semejantes, se proponen desde el doble efecto para algunas situaciones de estado de necesidad. Finalmente, en la tercera sección, entregaremos los criterios de una política criminal para distinguir y no encubrir exigencias deónticas en el estado de necesidad.

*Artículo recibido el 14 de septiembre de 2018 y aceptado para su publicación el 20 de noviembre de 2019.

** Abogado. Magíster en filosofía. Doctor en derecho (área: filosofía del derecho). Director del Instituto de Filosofía de la Pontificia Universidad Católica de Chile. rmadrid@uc.cl.

${ }^{* * *}$ Abogado. Magíster en derecho. Doctor en derecho (área: fundamentos del derecho penal). Profesor del Departamento de Derecho Penal y Procesal Penal de la Universidad de los Andes, Santiago-Chile.rmadrid@uc.cl.

Problema. Anuario de Filosofía y Teoría del Derecho, núm. 14, enero-diciembre de 2020, pp. 247-283 Ciudad de México, ISSN 2007-4387, se distribuye bajo una Licencia Creative Commons Reconocimiento-No Comercial-Sin Derivados 4.0 Internacional (CC BY-NC-ND 4.0). 
RAÚL MADRID RAMÍREZ / RODRIGO ANDRÉS GUERRA ESPINOSA

\title{
Palabras clave:
}

Doble efecto; estado de necesidad; consecuencialismo; absolutismo moral; universos éticos.

\begin{abstract}
:
This article aims to explain when the distinction between a greater or lesser evil responds to a consequentialist ethical universe or not under necessity defense. In addition, explain why the human life pondering is possible from the double effect principle, accepting the objectification of its parameters according to an action. Therefore, in the first section we deal with the concept of evil in a consequentialist and moral absolutist perspective. On the second section of this article, we explain the importance of these ethical universes in the evils pondering. Then, we contrast our reasoning with the solution proposed by the double effect doctrine under necessity cases. Finally, in the third section, we give a criminal policy criterion to understand the deontic demands under necessity.
\end{abstract}

\section{Keywords:}

Double Effect; State of Necessity; Consequentialism; Moral Absolutism, Ethical Universes. 
UNIVERSOS ÉTICOS Y LA METARREGLA DEL DOBLE...

Sumario: I. Punto de partida: universos éticos en el estado de necesidad. II. Concepto de "mal" en el estado de necesidad. III. Universos éticos y la metarregla del doble efecto. IV. Reflexiones finales. V. Bibliografía.

\section{PUNTO DE PARTIDA: UNIVERSOS ÉTICOS}

EN EL ESTADO DE NECESIDAD

Es una tarea de la filosofía del derecho penal demostrar la existencia de un vínculo entre los universos éticos (es decir, las diversas concepciones generales sobre el carácter moral del acto humano) y la concepción dogmático-penal en la resolución de situaciones trágicas o de conflicto vital en el estado de necesidad. ${ }^{1}$ Se trata, por lo tanto, de una materia previa a la interpretación de la norma que trata el tema en el derecho positivo chileno: el artículo 10, número 11, del Código Penal. ${ }^{2}$ Si bien existen diferentes definiciones del estado de necesidad, el núcleo de la institución apunta a situaciones excepcionales de peligro para determinados bienes jurídicos que sólo pue-

1 Respecto del contenido y las problemáticas que abarca el concepto de conflicto vital en el estado de necesidad, véase Miranda, Alejandro, "Consequentialism, the Action/Omission Distinction, and the Principle of Double Effect: Three Rival Criteria to Solve Vital Conflicts in Cases of Necessity", The American Journal of Jurisprudence, vol. 62, núm. 2, 2017, p. 210, enfile://C:/Users/profesor2/Downloads/ AMM_Consequentialism\%252c\%20action-omission\%20and\%20double\%20effect. $p d f$. Por su parte, se utiliza el concepto de situaciones trágicas de estado de necesidad para aludir a este tipo de situaciones en materia penal en Wilenmann von Bernath, Javier, "Imponderabilidad de la vida humana y situaciones trágicas de necesidad”, InDret, núm. 1, 2016, p. 1.

2 En este contexto, la disposición del artículo 10, número 11, dispone que está exento de responsabilidad criminal: "El que obra para evitar un mal grave para su persona o derecho o los de un tercero, siempre que concurran las circunstancias siguientes: 1a. Actualidad o inminencia del mal que se trata de evitar. 2a. Que no exista otro medio practicable y menos perjudicial para evitarlo. 3a. Que el mal causado no sea sustancialmente superior al que se evita. 4a. Que el sacrificio del bien amenazado por el mal no pueda ser razonablemente exigido al que lo aparta de sí o, en su caso, a aquel de quien se lo aparta siempre que ello estuviese o pudiese estar en conocimiento del que actúa". 
den contrarrestarse por medio de la lesión de otro bien jurídico. Se genera, en consecuencia, un conflicto entre bienes protegidos, intereses o males, porque no todos pueden coexistir en ese estado. ${ }^{3}$ Por esta razón, se requiere de un criterio axiológico que permita discernir en estos casos.

Tal circunstancia fáctica de peligro ocasiona que el agente, con el propósito de alcanzar su objetivo (evitar un riesgo actual o inminente), realice acciones que afecten otros bienes jurídicos, que pueden ser lesionados, e incluso sacrificados, para que el resto no perezca. ${ }^{4}$ Conocidos casos reflejan el problema, como el del capitán del barco que da la orden de arrojar al agua, toda o parte de la carga del navío para que éste no se hunda en una tempestad; el caso de quien se apodera de una cabalgadura ajena para llevar a un enfermo grave ante un médico, al no existir otro medio de transporte en una zona rural aislada; el caso de quien, huyendo de una bestia, cruza

3 La doctrina dominante se declina en favor de un conflicto entre males, especialmente en consideración a la regulación del artículo 10, número 7, en Fuentes, Dánae, La ponderación de los males en el estado de necesidad, Santiago, LegalPublishing, 2009, pp. 59-61. Posiciones a favor de un conflicto entre intereses se pueden observar en Cousiño Mac Iver, Luis, Derecho penal chileno. Parte general, Santiago, Editorial Jurídica de Chile, 1979, t. II, p. 348, y entre bienes, Cury, Enrique, Derecho penal. Parte general, 7a. ed., Santiago, Ediciones Universidad Católica de Chile, 2005, p. 377; Etcheberry Orthusteguy, Alfredo, Derecho penal, 3a. ed., Santiago, Editorial Jurídica de Chile, 1998, t. I, pp. 266-268; Vargas Pinto, Tatiana, “ ¿Tiene la necesidad cara de hereje? Necesidad justificante y exculpante del artículo 10, núm. 11", en Van Weezel, A. (ed.), Humanizar y renovar el derecho penal. Estudios en memoria de Enrique Cury, Santiago, LegalPublishing, 2013, p. 749; Novoa Monreal, Eduardo, Curso de derecho penal chileno. Parte general, 3a. ed., Santiago, Editorial Jurídica de Chile, 2005, t. I, p. 355; Náquira, Jaime, Derecho penal. Teoría del delito I, Santiago, Editorial McGraw-Hill, 1998, p. 256; Politoff Lifschitz, Sergio y Ortiz Quiroga, Luis, Texto y comentario del Código Penal chileno, Santiago, Editorial Jurídica de Chile, 2002, t. I, p. 140, entre otros. Por su parte, en la doctrina civil, respecto de la posibilidad de ponderar intereses o daños con el objeto de evitar un mal mayor, véase Barros Bourie, Enrique, Tratado de responsabilidad extracontractual, Santiago, Editorial Jurídica de Chile, 2006, pp. 138 y 139; Alessandri R., Arturo, Tratado de derecho civil. Partes preliminar y general, 7a. ed., Santiago, Editorial Jurídica de Chile, 2005, t. I, p. 443.

4 En esta línea, podemos entender por sacrificio el menoscabo íntegro del bien jurídico en cuestión y por lesión una afectación parcial de éste, susceptible de subsunción en algún tipo penal. 
UNIVERSOS ÉTICOS Y LA METARREGLA DEL DOBLE...

predio ajeno para evitar un mal grave a sí mismo. ${ }^{5}$ Nos ocuparemos aquí sólo de aquellos casos de estado de necesidad agresivo en los cuales pueda ponerse en juego la vida de seres humanos inocentes. ${ }^{6}$

Actualmente es habitual aceptar una corriente neutralista, carente de valoraciones axiológicas en el estado de necesidad. ${ }^{7}$ En este contexto, el principio del interés preponderante se presenta como un criterio de razonamiento "en situaciones de conflicto [donde] el Derecho debe racionalmente inclinarse por el mal menor [en] cualquier propuesta de justificación .... ${ }^{8}$ Considerando este antecedente, acciones lesivas como la destrucción de aeronaves o centros militares en estado de necesidad, necesariamente unidas a la muerte de inocentes, parecen ser indispensables. Así, nos parece adecuado preguntar por la posibilidad de un fundamento relativo a la ponderación de males en el estado de necesidad; es decir, en atención al principio del mal menor, que sea una guía razonable, y no necesariamente vinculada al utilitarismo clásico. ${ }^{9}$ La razón de ello es que el fundamento del mal menor únicamente se puede explicitar a través del universo ético que guía la aplicación del principio en cuestión.

5 La disposición del artículo 145 del CP chileno establece ciertas excepciones respecto del delito de violación de morada. El artículo establece: "La disposición del artículo anterior no es aplicable al que entra en la morada ajena para evitar un mal grave a sí mismo, a los moradores o a un tercero, ni al que lo hace para prestar algún auxilio a la humanidad o a la justicia. Tampoco tiene aplicación respecto de los cafés, tabernas, posadas y demás casas públicas, mientras estuvieren abiertos y no se usare de violencia inmotivada". Énfasis añadido.

6 Esto porque hemos realizado un tratamiento de las generales del estado de necesidad, sobre los cuales se asienta el desarrollo del presente estudio, en Guerra Espinosa, Rodrigo, Estado de necesidad como conflicto de intereses: una propuesta de interpretación desde la inevitabilidad, Santiago-Chile, Ara Editores, 2017.

7 Guerra Espinosa, Rodrigo, "Principio de no contradicción en el estado de necesidad”, Revista de Derecho (Valdivia), vol. 30, núm. 2, 2017, pp. 368 y ss., disponible en: http://dx.doi.org/10.4067/S0718-09502017000200016.passim.

8 Molina Fernández, Fernando, Estado de necesidad y justificación penal: ¿es lícita la tortura en situaciones extremas?, Colombia, Grupo Editorial Ibáñez, 2009, p. 125.

9 Guerra Espinosa, Rodrigo Andrés, “Ambivalencia en el principio del interés preponderante", Revista de Derecho de la Pontificia Universidad Católica de Valparaíso, 2017, núm. 49, pp. 187 y ss., disponible en: http://dx.doi.org/10.4067/S071868512017000200187. 
En el caso de la dogmática chilena, aunque no existe un tratamiento expreso de la materia, se puede observar la presencia de una apelación ética en el planteamiento de diversos autores. Así, Mañalich dispone, a propósito del caso de la tabla de Carneádes, que

...la situación deóntica resultante, entonces, es que tanto A como B deben abstenerse de sujetar la tabla para así evitar causar la muerte de otro. Apelar al argumento consecuencialista de que sería conveniente que el respectivo ordenamiento jurídico hiciera lo posible para el salvamento de al menos uno de los dos, es incompatible con el hecho de que uno y otro son, simultáneamente y en igual medida, tanto destinatarios de la prohibición de matar a otro como beneficiarios de la protección dispensada por ésta. ${ }^{10}$

Mañalich observa en esta modalidad del caso una contraposición, que difícilmente puede ser resuelta a través de un mero argumento consecuencialista, y del cual se sigue la prohibición de matar a un inocente. Y por análoga razón, se trata de un razonamiento en un contexto determinado (la decisión de sacrificar la vida de un inocente), y cuyo sustento es contrario al consecuencialismo. En atención al artículo 10, número 11, el cual sostiene que es posible provocar un mal para evitar un mal grave en contra de nuestra persona, derechos o los de un tercero, nos parece que sería relevante considerar que este razonamiento es parte de la dogmática penal.

Es incuestionable que la distinción entre estos universos éticos tiene importancia en casos de estado de necesidad en que se encuentra en juego la integridad física de personas. El modelo kantiano y la tradición moral clásica niega la posibilidad de utilizar al ser humano como un mero instrumento. Por eso, para el consecuencialismo esta premisa es virtualmente absoluta dependiendo de las consecuencias de la acción en el estado de necesidad. ${ }^{11}$ Sin embargo,

10 Mañalich, Juan Pablo, "Normas permisivas y deberes de tolerancia”, en Mañalich, J. P. (coord.), La antijuricidad en el derecho penal. Estudios sobre las normas permisivas y la legítima defensa, Montevideo-Buenos Aires, Editorial B de F., 2013, p. 282.

11 McCormick, Richard, "El principio del doble efecto", trad. de A. Goñi, Concilium 120,1976, p. 578; McCormick, Richard, “Ambiguity in Moral Choice”, en McCormick, 
UNIVERSOS ÉTICOS Y LA METARREGLA DEL DOBLE...

la trascendencia de esta cuestión en torno a los universos éticos ha sido relativizada en lo que concierne a la "aceptación o la negación de las prohibiciones morales absolutas". ${ }^{12}$ Así, siguiendo a Finnis, sencillamente se rechazan o desaparecen incluso en la filosofía del derecho de autores como Rawls, Nagel, Dworkin, entre otros. ${ }^{13}$

En consonancia con esta problemática, Sánchez-Ostiz, en la dogmática penal, ha sostenido que la ponderación de principios no puede excluir la dignidad humana o las prohibiciones morales absolutas, porque la dignidad "resalta el carácter absoluto del principio". ${ }^{14}$ Esta noción nos lleva a entender que no es posible la conversión del ser humano en un valor o precio, sino que se encuentra sobre todo esto. El hombre carece de precio no porque sea un fin en sí, sino porque es espiritual. Por ello, existe en su modelo de política criminal una metarregla de prioridad condicionada, donde la dignidad se encuentra por encima del radical de la libertad y la socialidad, porque le otorga la característica más propia a la esencia de la persona. ${ }^{15}$

Modelos como los de Sánchez-Ostiz han contribuido en la dogmática penal, por una parte, a apartar la atención del consecuencialismo, y a despertar el interés por una mirada antropológica del hombre. Ello se advierte también en la doctrina chilena. ${ }^{16}$ En este tiempo, a modo de ejemplo, se ha trasladado la problemática a cuestiones propias del estado de necesidad. Así, en la práctica, se ha renunciado a un esfuerzo por lograr una mayor coherencia conceptual

R. y Ramsey, P. (eds.), Doing Evil to Achieve Good. Moral Choice in Conflicts Situations, Chicago, Loyola University Press, 1978, pp. 38, 41 y 45.

12 Miranda, Alejandro, El principio del doble efecto, Hildesheim, Georg Olms Verlag, 2014, p. 129.

13 Finnis, John, Natural Law and Natural Rights, Oxford, Clarendon Press, 1993, pp. 9-12.

14 Sánchez-Ostiz, Pablo, "Principios y reglas como base para un modelo argumentativo intercultural de derecho penal”, en Sánchez-Ostiz, P. (coord.), Multiculturalismo y derecho penal, Pamplona, Thomson Reuters-Aranzadi, 2012, p. 111.

15 Sánchez-Ostiz, Pablo, Fundamentos de política criminal. Un retorno a los principios, Madrid, Marcial Pons, 2012b, p. 61.

${ }_{16}$ Guerra Espinosa, Rodrigo, Estado de necesidad como conflicto de intereses, cit., p. 246 , nota 708 . 
con la filosofía del derecho, dando entrada a una lógica de neutralización de estos universos o, así como beneficiando, la exclusión de un razonamiento coherente con las premisas kantianas en situaciones de estado de necesidad.

Mientras, se ha establecido en la dogmática chilena una posición que, si bien reconoce los fundamentos de la imponderabilidad de la vida humana, y considera que "la vida es siempre una parte esencial de la propia libertad, por lo que el sacrificio de ésta no puede ser exigido en estado de necesidad", porque "la vida puede ser vinculada a la estructura de condición de posibilidad jurídica que tiene el mantenimiento del hombre... como condición de ejercicio de cualquier otro derecho", ${ }^{17}$ acepta la aplicación del estado de necesidad en clave consecuencialista en comunidades de peligro con distribución unilateral de posibilidades de salvación. ${ }^{18}$

\section{CONCEPTO DE “MAL” EN EL ESTADO DE NECESIDAD}

El interés de los académicos hispanohablantes en la interpretación del concepto de mal en el estado de necesidad se origina en "diálogo" con la dogmática y la filosofía alemanas, como un modo de entregar seguridad en su interpretación y reducir la complejidad del término, porque no existe certeza respecto de la extensión del mismo. Es un concepto difícil de interpretar, que podría acogerse a un espacio de tolerancia de la imprecisión, ${ }^{19}$ en cuanto puede desembocar en una

17 Wilenmann, Javier, “Imponderabilidad de la vida humana..., cit., p. 26.

18 Se puede observar un tratamiento de estas comunidades de peligro con distribución unilateral de posibilidades de salvación en Wilenmann, Javier, "Imponderabilidad de la vida humana...", cit., pp. 27 y ss.

19 La tolerancia de la imprecisión (tolerability of imprecision) se traduce en no regular los efectos justificantes o exculpantes del estado de necesidad en el ordenamiento jurídico positivo. Pues bien, la dogmática debe establecer cuáles son los criterios que permiten determinar dichos efectos. Así pues, es tarea de los académicos construir sistemas comprensivos que permitan, desde sus premisas axiológicas o filosóficas, entregar una solución a la diferenciación, véase Gur-Arye, Miriam, 1992: "¿Should a Criminal Code Distinguish Between Justification and Excuse?", Canadian Journal of Law and Jurisprudence, vol. V, núm. 2, 1992, p. 230 en http://heinonline.org/HOL/Page?handle=hein.journals/caljp5\&div=20\&g_sent=1 
UNIVERSOS ÉTICOS Y LA METARREGLA DEL DOBLE...

ponderación de intereses, bienes jurídicos, e incluso efectos; en este caso, en situaciones que podrían afectar a terceros que no han provocado la situación de peligro que se pretenda enfrentar. ${ }^{20}$

Por mal puede entenderse la "lesividad del hecho para los bienes jurídicos"21 que se vean menoscabados o puestos en peligro, sin riesgo de observar en su contenido deóntico una amenaza para su compresión, excepto en los casos en los que una razón proporcionada sea suficiente para resolver el conflicto. Se trata, pues, de un concepto que puede responder tanto a razones meramente proporcionadas, como a algún contenido deóntico que guie su interpretación. ${ }^{22}$

Ahora bien, el artículo 10, número 11, establece expresamente que "el mal causado no sea sustancialmente superior al que se trata de evitar". Así, la ponderación normativamente se realiza entre males y no intereses. Aceptar la equivalencia entre intereses y males, aparentemente, no supondría entrar en conflicto con la ponderación, considerando que el estado de necesidad es un conflicto de intereses. En la dogmática chilena y española no existe un mayor debate al respecto, porque diversos autores consideran que la pon-

\&collection=journals\#217; Greenawalt, Kent, "Distinguishing Justifications from Excuses", Law \& Contemporary Problems, vol. 49, núm. 3, 1986, p. 107, disponible en: http://scholarship.law.duke.edu/cgi/viewcontent.cgi?article $=3860 \&$ context $=$ lcp .

20 En este contexto, en la dogmática chilena se presentan resquemores con relación a la justificación de un estado de necesidad que pueda afectar los derechos de terceros que no crea la situación de peligro. Así las cosas, nuestra disposición reconoce "la posibilidad de una exculpación por estado de necesidad en una situación de peligro para bienes fundamentales de personas no estrechamente vinculadas con el autor de la respectiva acción de salvaguarda", a diferencia de lo previsto en el Código Penal alemán, Mañalich, Juan Pablo, "El estado de necesidad exculpante. Una propuesta de interpretación del artículo 10, número 11 del Código Penal Chileno", en Van Weezel, A. (ed.), Humanizar y renovar el derecho penal. Estudios en memoria de Enrique Cury, Santiago, Legal Publishing, 2013, p. 735.

21 Molina Fernández, Fernando, op. cit., p. 28, nota 31.

22 En este contexto, es claro que el derecho no puede proteger valores puramente éticos o explicar la aplicación de eximentes desde estos parámetros. Sin embargo, existen situaciones excepcionales en las cuales existen metarreglas que permiten resguardar la dignidad humana en situaciones de conflicto vital; esto es, relativas a la posibilidad del sacrificio de vidas humanas. 
deración debe ser realizada entre males..$^{23}$ Lo que importa es saber si es un mal físico o moral.

Otros observan en la palabra mal un concepto amplio que contiene una multiplicidad de elementos que van más allá de los bienes jurídicos, con objeto de determinar si la conducta está o no justificada. Así, el concepto de mal nos permite una mayor amplitud, porque no sólo contemplaría el daño causado a un bien particular, sino todas las circunstancias fácticas que producen dicho menoscabo. ${ }^{24} \mathrm{~A}$ pesar de la referencia legal al mal, la entidad de éste sólo puede ser determinada por medio de la ponderación de intereses Si bien es aceptable que la ponderación debe ir más allá de una comparación de bienes, no podemos olvidar que el concepto de mal "se mide por la lesividad del hecho para los bienes jurídicos". ${ }^{25}$

Por eso, para llegar a este resultado no debemos descuidar la serie de factores que comprende el término interés. De ahí que, a nuestro parecer, el hecho de sostener que el interés y el mal resultan equivalentes es problemático. En efecto, si tal configuración no merece diferenciación, la lesividad del hecho desempeñaría la única función ordenadora en el análisis de una situación de necesidad. Este razonamiento nos retrotraería a una ponderación esquemática de bienes.

Interés es un concepto que tiene correlación, dogmáticamente, con todo principio, bien, colisión de valores o deberes. ${ }^{26}$ Esta formulación amplia presenta críticas en la dogmática porque no entrega una respuesta precisa respecto de qué es un interés. Así pues, nos

23 Sin embargo, Wilenmann sostiene, criticando la teoría del interés preponderante, que el fundamento de la justificación en el estado de necesidad se encuentra en el principio de solidaridad, y rechaza la posibilidad de búsqueda del mal menor ante el posible riesgo de caer en una lectura utilitarista Se observa una crítica en torno a este modelo en Guerra Espinosa, Rodrigo Andrés, "Ambivalencia en el principio...", cit., passim.

24 Fuentes, Dánae, op. cit., pp. 58-61.

25 Molina Fernández, Fernando, op. cit., p. 28, nota 31; Sánchez-0stiz, Pablo, Fundamentos de Política criminal..., cit., p. 250.

26 Lenckner, Theodor, Der rechtfertigende Notstand. Zur Problematik der Notstandregelung im Entwurf eines Strafgesetzbuches, Tübingen, Mohr Siebeck, 1965, pp. 124 y 125; Martínez Cantón, Silvia, La ponderación en el estado de necesidad, León, Universidad de León, Secretariado de Publicaciones, 2006, p. 255. 
UNIVERSOS ÉTICOS Y LA METARREGLA DEL DOBLE...

parece que es más que un "recurso literario que permitiría una redacción mucho más brillante en el ámbito del estado de necesidad" 27 propio del $\S 34$ del CP alemán, en contraste con el modelo chileno o español, que utiliza la palabra mal, porque nos recuerda "que la ponderación de intereses debe ser compleja y atender a todo lo que está en juego". ${ }^{28}$

El concepto de interés alude a un conjunto amplio de elementos positivos para la sociedad y el individuo que merecen protección en el sistema jurídico. ${ }^{29}$ Elementos que se pueden sintetizar en una política criminal que retorne a los principios de legalidad, seguridad social y respeto a la dignidad humana. Así, la ponderación de estos principios permite entregar operatividad a la máxima o cúspide de todas las justificantes: el principio del interés preponderante. ${ }^{30}$

Ahora bien, en el concepto de "interés" podría parecer paradigmático hablar de efectos colaterales o indirectos. El término indirecto o colateral, aparentemente, posee una unidad semántica que tiene correlación con el concepto de bien o mal. Entre el término "interés" y el concepto "efectos colaterales" pareciera existir una estructura de contraste. Pero necesitamos profundizar en la noción de efecto, con objeto de determinar si puede ser subsumido en el concepto de interés. Pues bien, partimos de la premisa de que toda acción realizada en estado de necesidad es una actio dúplex, porque reviste tanto una protección como una agresión a intereses de terceros. ${ }^{31}$ Sabido es en la filosofía y dogmática que tal acción permite aislar estos efectos. ${ }^{32}$

27 Martínez Cantón, Silvia, op. cit., p. 286.

28 Molina Fernández, Fernando, op. cit., p. 29.

29 Martínez Cantón, Silvia, op. cit., p. 288.

30 Molina Fernández, Fernando, op. cit., p. 40.

31 Baldó Lavilla, Francisco, Estado de necesidad y legítima defensa: un estudio sobre las «situaciones de necesidad» de las que derivan facultades y deberes de salvaguarda, Barcelona, Bosch, 1994, p. 17.

32 En este sentido, "a la necessitudo cum adjunctione pertenecerían, entre otros, todos los casos que caen hoy, para nosotros, bajo las categorías de estado de necesidad justificante y exculpante. Este estado de necesidad es, por eso, si lo comparamos a la necessitudo absoluta, un estado de necesidad con limitaciones, porque el necesitado, pese al peligro que sobre él se cierne, tiene siempre una elección. Posiblemente fue Aristóteles el primero en escribir: el afectado puede elegir entre el 
La expresión actio duplex acepta que de una misma acción se puede derivar tanto una lesión de bienes jurídicos como una salvaguarda de ellos. De este modo, el concepto puede aplicarse a cualquier sistema jurídico que tenga que enfrentar casos de estados de necesidad. Es este último el que materializa la plataforma conceptual del estado de necesidad, y no alguna circunstancia aislada que define la elección que causa una lesión. ${ }^{33}$ La complejidad de estas acciones va más allá de una enunciación normativa de reglas prohibitivas y permisivas, porque en estos casos se debe considerar toda la multiplicidad de factores en cuestión. En esta línea, sorteando un análisis de bienes o males, la apreciación de la situación de peligro, existencia de deberes y la existencia de efectos colaterales deben ser tenidos en consideración cuando se enfrenta la posibilidad de justificar un hecho lesivo.

Sin embargo, esta constatación "no responde a la cuestión de por qué. En virtud de la mencionada «preponderancia» de intereses, unos deben "prevalecer» sobre los otros —entendiéndose justificada la actio dúplex-", ${ }^{34}$ lo que únicamente se puede responder a través de principios axiológicos. Precisamente, en este contexto, uno de los principios axiológicos que ha desarrollado un tratamiento de los efectos colaterales es el doble efecto. Nos hemos, pues, preguntado si este principio podría ser exportado desde el segundo nivel de reglas de justificación al primero y permitir, así, un análisis objetivo que no recurra a la oscura noción de intención. ${ }^{35}$ Sin embargo, esto

acto con el que evita el mal amenazado o el mal con el que se lo amenaza. El acto con el que se evita el mal que se conoce desde Aristóteles como acción «mixta» (actio mixta)"; Hruschka, Joachim, imputación y derecho penal. Estudios sobre la teoría de la imputación, 2a. ed., Buenos Aires, Editorial B de f, 2009, pp. 263 y 264.

33 Molina Fernández, Fernando, op. cit., p. 23.

${ }^{34}$ Baldó Lavilla, Francisco, op. cit., p. 40.

35 Ello, sobre todo en lo que respecta a comprender el doble efecto como una regla de aplicación general en materia jurídico-penal, véase Miranda Montecinos, Alejandro, "El principio del doble efecto y su relevancia en el razonamiento jurídico", Revista Chilena de Derecho, vol. 35, núm. 3, 2008, passim, disponible en: http://www. scielo.cl/scielo.php?pid=S0718-34372008000300005\&script=sci_arttext. Por su parte, no debemos olvidar las críticas respecto de este punto realizadas, en la interpretación de la legítima defensa, en Bascuñán, Antonio, "La píldora del día después ante la jurisprudencia”, Revista de Estudios Públicos, núm. 95, 2004, p. 68, nota 43, 
UNIVERSOS ÉTICOS Y LA METARREGLA DEL DOBLE...

podría desarticular, aparentemente, el dolo de las consecuencias seguras e imposibilitar imputar homicidio por el mero conocimiento. ${ }^{36}$

No obstante, el fundamento del principio nos parece que, siguiendo una interpretación jurídico-objetiva de la intención, ${ }^{37}$ más bien propia del concepto de conocimiento en materia jurídico-penal, podría determinar la preponderancia del efecto positivo de la acción realizada. Si se considera la voluntad indirecta en esta línea interpretativa, ésta concurre, por ejemplo, en casos como los consecutivos: cuando un sujeto para salvar la vida de la madre induce el parto como medida terapéutica, cuando la gestante se encuentre con riesgo de muerte de continuar la gravidez; o cuando un sujeto inyecta a otro pequeñas dosis de morfina para el tratamiento paliativo de una enfermedad terminal y en condiciones de que ese suministro pueda acelerar o desencadenar la muerte en el paciente.

El primero de los argumentos en favor de esta posición es la primera causal del artículo 119 del Código Sanitario (en adelante CS), y el artículo 16, inciso cuarto, de la Ley $20.584,{ }^{38}$ respectivamente,

disponible en: https://www.cepchile.cl/la-pildora-del-dia-despues-ante-la jurispru dencia/cep/2016-03-04/093409.html. Sin embargo, la mayor parte de la tradición del doble efecto rechaza la aplicación del mismo en la legítima defensa.

36 Punto que ha sido desarrollado con mayor énfasis en la segunda sección de este trabajo. No obstante, si bien el dolo de las consecuencias seguras o dolo indirecto tiene aceptación en la dogmática penal, debemos indicar que su reconocimiento no deja de ser controvertido en la filosofía analítica. Respecto de este conflicto entre el concepto de dolo indirecto o de las consecuencias seguras, Miranda indicó que, como defensor del principio del doble efecto, "el concepto general de dolo de las consecuencias seguras nunca [exige la ilicitud del acto] para que se configure", dándolo por supuesto; Miranda Montecinos, Alejandro, "El principio del doble efecto y su relevancia...”, cit., p. 512, nota 114. Crítica que busca evitar establecer una responsabilidad objetiva por un acto lícito que tenga como efecto colateral la muerte de inocentes.

37 Miranda realiza un correctivo al principio del doble efecto en el caso de la histerectomía objetivizando la intención; véase Miranda Montecinos, Alejandro, "Eutanasia, suicidio asistido y principio del doble efecto. Réplica al profesor Rodolfo Figueroa", Rev. méd. Chile, vol. 140, núm. 2, 2012, p. 263. Consideramos que esta perspectiva tendría interrelación con una mirada cognitiva del dolo ajena a un derecho penal del sentimiento.

38 Artículo 16: "La persona que fuere informada de que su estado de salud es terminal, tiene derecho a otorgar o denegar su voluntad para someterse a cualquier 
Esta revista forma parte del acervo de la Biblioteca Jurídica Virtual del Instituto de Investigaciones Jurídicas de la UNAM

que no pueden ser eludidas por quienes no las compartan "acudiendo a la disposición general [del] estado de necesidad". ${ }^{39}$ Estas disposiciones no son capaces por sí solas de resolver el conflicto en cuestión por el grado de abstracción de la regla. Por ello, requieren de complemento a través de la lex artis, ${ }^{40}$ pero también de criterio axiológico que explique por qué la vida de un inocente puede verse menoscabada. Es decir, el interés del no nacido en una situación de peligro para la vida de la madre en el embarazo o del paciente con una enfermedad terminal puede ser objeto de los efectos colaterales (negativos) de una intervención médica. ${ }^{41}$

tratamiento que tenga como efecto prolongar artificialmente su vida, sin perjuicio de mantener las medidas de soporte ordinario. En ningún caso, el rechazo de tratamiento podrá implicar como objetivo la aceleración artificial del proceso de muerte.

Este derecho de elección no resulta aplicable cuando, como producto de la falta de esta intervención, procedimiento o tratamiento, se ponga en riesgo la salud pública, en los términos establecidos en el Código Sanitario. De esta circunstancia deberá dejarse constancia por el profesional tratante en la ficha clínica de la persona.

Para el correcto ejercicio del derecho establecido en el inciso primero, los profesionales tratantes están obligados a proporcionar información completa y comprensible.

Las personas que se encuentren en este estado tendrán derecho a vivir con dignidad hasta el momento de la muerte. En consecuencia, tienen derecho a los cuidados paliativos que les permitan hacer más soportables los efectos de la enfermedad, a la compañía de sus familiares y personas a cuyo cuidado estén y a recibir, cuando lo requieran, asistencia espiritual". Énfasis añadido.

39 Molina Fernández, Fernando, op. cit., p. 52.

40 Horvitz Lennon, María Inés y Soto Piñeiro, Miguel, “Consideraciones críticas sobre la regulación del delito de aborto en el anteproyecto de nuevo Código Penal elaborado por el foro del Ministerio de Justicia", Revista de Estudios de la Justicia, núm. 9, 2007, p. 88, nota 28; Ossandón Widow, María Magdalena, "Aborto y justificación”, Revista Chilena de Derecho, vol. 39, núm. 2, 2012, pp. 334 y 335.

41 Perspectiva que tiene reconocimiento en el Departamento de Ética del Consejo General del Colegio Médico de Chile en lo relativo a la temática del Aborto: Interrupción del Embarazo como Medida Terapéutica en Casos de Gestantes con Riesgo de Muerte al Continuar la Gravidez, de febrero de 2003, porque persiste el reconocimiento de situaciones en las que, inevitablemente, no existe otra solución que interrumpir la gestación. Así, "en estos casos, la intervención —cuya intención es obviamente preservar la vida de la madre- está orientada, al menos, por los principios de beneficencia, de no maleficencia y el respeto a la autonomía de la madre. Si se vulneran los derechos del hijo que está en el seno materno, ello ocurrirá como producto de un acto proporcionado, que lo afecta indirectamente, por cuanto no fue 
UNIVERSOS ÉTICOS Y LA METARREGLA DEL DOBLE...

Está claro que, en el primer caso, la intervención no puede no tener por objeto provocar un aborto o, en el segundo, permitir la eutanasia. Pero el grado de indeterminación de estas reglas es un caso marginal que, en las justificantes de tercer nivel, requiere de fundamento. ${ }^{42}$ Hacerlo de otra forma supondría transgredir el principio de legalidad. Pues bien, negaríamos al legislador su competencia para "resolver los conflictos sociales de la manera que crea más adecuada". ${ }^{43}$ Nos parece que el tenor de las disposiciones chilenas enunciadas es claro. Así pues, en éstas no se permite en una intervención que tenga por finalidad provocar un aborto o dar lugar a la eutanasia. $^{44}$

Si se considera la posibilidad de terminar con la vida de un inocente sólo en atención a si es fuente de peligro, nos encontraríamos frente a una interpretación que circunscribe forzadamente a los parámetros del estado de necesidad defensivo. Una interpretación de estas características es sostenida por Bascuñán, porque —según este autor - la extensión del estado de necesidad defensivo no sólo se aplica a situaciones en las que aparentemente el no nacido es la fuente de peligro, sino también a "todo embarazo no consentido por la mujer [porque] el embrión o feto es una amenaza inocente ... para sus intereses personales [o autonomía reproductiva]". ${ }^{45}$

realizado con la intención primaria de dañarlo sino que procurando un mayor bien. Esta acción se denomina de doble efecto y éticamente se valida por el sentido de lo intentado y no de lo que escapa a la intención". Énfasis añadido. Ossandón Widow, María Magdalena, “Aborto y justificación”, cit., p. 335, nota 509. Por su parte, respecto de los tratamientos paliativos se ha reconocido por el Grupo de Estudio de Ética Clínica de la Universidad Católica de Chile que el uso apropiado de analgésicos, con el objeto de atenuar el dolor y no con la finalidad de acelerar la muerte, es una conducta justificada desde el doble efecto, véase Zúñiga Fajuri, Alejandra, "Derechos del paciente y eutanasia en Chile”, Revista de Derecho, vol. XXI, núm. 2, 2008, p. 125, disponible en: http://www.scielo.cl/pdf/revider/v21n2/art05.pdf.)

42 Molina Fernández, Fernando, op. cit., pp. 49 y 50.

43 Ibidem, p. 52; Ossandón Widow, María Magdalena, “Aborto y justificación”, cit., p. 334 .

44 Candano Perez, Mabel y Guerra Espinosa, Rodrigo, "Responsabilidad penal médica: consideraciones en la aplicación del principio del doble efecto", Rev.Med. Electrón, vol. 40, núm. 4, 2018, pp. 1232-1244.

45 Bascuñán, Antonio, op. cit., p. 71. 
Pero en estos casos no parece existir en realidad una "distribución justa de riesgos, en una situación en que no hay forma alguna de asignar responsabilidad". ${ }^{46}$ Sin embargo, ello no implica simplemente "tomar la decisión consecuencialistamente más sensata para minimizar las consecuencias de la tragedia". ${ }^{47}$ Es por eso que debemos de aceptar una premisa moral absolutista, analizar la posibilidad de aplicar el doble efecto como una metarregla de prioridad condicionada. A partir de ello, el resguardo del núcleo esencial de la dignidad humana reconoce una limitante en casos de estado de necesidad. ${ }^{48}$

En este orden de ideas, el actual artículo 119 del CS cierra la posibilidad de trasladar la problemática del aborto al estado de necesidad defensivo, porque genera un efecto oclusivo ante el estado de necesidad del artículo 10, número 11, o el mismo artículo 10, número $10 .{ }^{49}$ Se trata, pues, de excluir la posibilidad de convertir al estado de necesidad en una ley general para estos casos, así como el sentido de una expresión como riesgo vital restringe - en la primera causal del actual artículo 119 de la Ley 21.030 - toda intervención constitutiva de aborto. Esta última consideración se desconoció en un sector de la dogmática, con la antigua regulación que presentaba el artículo 119, al indicar que no es posible "enfrentar lo estipulado en el artículo 119 Código Sanitario con otras disposiciones contrapuestas, pues no existe una regulación permisiva en esta materia",50

46 Wilenmann, Javier, “Imponderabilidad de la vida humana..., cit., p. 35.

47 Idem.

48 Sin embargo, no se trata de desconocer casos de laboratorio en los cuales inevitablemente podemos plantear la posibilidad de matar directamente a inocentes. Así las cosas, Nozick crea un caso de laboratorio en el cual un agente arroja a un tercero contra un sujeto que se encuentra en el fondo de un pozo. Pues bien, este se pregunta si sería posible que el sujeto - al fondo del pozo - con una pistola de rayos desintegre el cuerpo del agente que cae antes de que lo mate. Esto, en el supuesto que el tercero arrojado pueda sobrevivir con la caída sobre el sujeto que se encuentra en el fondo del pozo; véase Nozick, Robert, Anarchy, State and Utopia, New York, Basic Books, 1974, p. 34.

49 Molina Fernández, Fernando, op. cit., p. 16.

50 Ossandón Widow, María Magdalena, "Aborto y justificación”, cit., p. 335. Ello, incluso en atención a la posible causal de inexigibilidad de otra conducta en los casos de violación. Con todo, esta última causal no justifica la realización de la acción, sino más bien la exculparía. 
UNIVERSOS ÉTICOS Y LA METARREGLA DEL DOBLE...

sosteniendo que "la función de dicha regulación es determinar los límites de lo que se considera riesgo permitido y, por ende, objetivamente atípico", ${ }^{11}$ indicando que "en el marco de la actuación médica son lícitas las conductas terapéuticas que indirectamente pueden derivar en un aborto". ${ }^{52}$

Nos parece que sostener la posibilidad de un aborto indirecto en la atipicidad niega el hecho de que efectivamente se está causando justificadamente la muerte del no nacido por efecto colateral, y conlleva el riesgo de inducir a pensar que su vida estaría condicionada al consentimiento de la madre o la necesidad terapéutica..$^{53}$ Consideramos que en casos de peligro existe un conflicto de intereses, porque el consentimiento de la madre o la necesidad terapéutica sólo son factores que se deben ponderar cuando se termina con la vida del nasciturus, que es valiosa por sí misma para el ordenamiento jurídi-

51 Ossandón Widow, María Magdalena, “Aborto y justificación”, cit., p. 336; Ossandón Widow, María Magdalena, "Regulación penal del aborto consentido y dignidad humana”, en Aguirrezabal, M. y Bertelsen, S. (eds.), El aborto. Perspectiva filosófica, jurídica y médica. Cuadernos de extensión jurídica 27, Santiago, Universidad de los Andes, 2015, p. 160.

52 Ossandón Widow, María Magdalena, “Aborto y justificación”, cit., p. 336. Por su parte, se observa un reconocimiento del doble efecto en la práctica médica en casos en los cuales el paciente incluso no puede prestar su consentimiento, en Silva Sánchez, Jesús María, "Los documentos de instrucciones previas de los pacientes (artículo 11.1, Ley 41/2002) en el contexto del debate sobre la (in)disponibilidad de la vida", La Ley. Revista Jurídica Española de Doctrina, Jurisprudencia y Legislación, 2003, p. 1666. Asimismo, existe reconocimiento de la aplicación de este principio en Bertelsen Simonetti, Soledad y García Palominos, Gonzalo, "La protección del derecho a la vida y el estatuto del no nacido en el sistema interamericano de derechos humanos", en Aguirrezabal, M. y Bertelsen, S. (ed.), El aborto. Perspectiva filosófica, jurídica y médica, Cuadernos de extensión jurídica, núm. 27, Santiago, Universidad de los Andes, 2015, p. 188. Estos últimos autores sostienen que "el actual modelo chileno... penaliza el aborto directo, pero permite el acto médico tendiente a salvar a la madre que pudiera tener como consecuencia indirecta la muerte de la criatura (Artículo 119 CS)”.

53 En esta línea, "el consentimiento sólo responde al principio de ausencia de interés cuando excluye la propia lesividad del hecho, y con ello la fundamentación positiva de la prohibición (el tipo), lo que inmediatamente nos sitúa al margen del campo propio de las causas de justificación. Si su concurrencia justifica, porque sigue habiendo un bien lesionado, es un interés más a ponderar en el conflicto"; Molina Fernández, Fernando, op. cit., p. 25. 
co. ${ }^{54}$ La intervención médica en una situación de peligro de muerte para la madre sólo se permite en la medida en que la acción se dirija a su salvación; su finalidad no es abortiva (artículo 119) porque la interrupción del embarazo busca evitar, con su consentimiento, un peligro para su vida. Sin embargo, para comprender esta finalidad es necesario incorporar un principio axiológico que nos explique por qué es posible realizar acciones que puedan tener como resultado la muerte eventual del nasciturus.

El principio del doble efecto sería ese criterio de justificación, porque exige acreditar la existencia de un peligro cierto de muerte, la inexistencia de otro medio menos lesivo para enfrentar el peligro, la realización de una acción intrínsecamente buena y, finalmente, una proporción entre el efecto intentado y el efecto colateral o preteritencional de la acción realizada. ${ }^{55}$ Esta posición doctrinal resulta compatible con la interpretación que aquí hemos tratado de fundamentar en torno al artículo 119 del CS, porque el doble efecto no tendría que lidiar con el problema del dolo de las consecuencias seguras, sino más bien con una lectura adecuada de la norma. De lo contrario, el argumento tendría por base un criterio funcionalista que, centrado en los deberes de la profesión del médico según el estado de la ciencia, no explicaría cuál es el criterio de valoración axiológico que permite terminar con la vida del nasciturus como efecto conocido y tolerado.

Así pues, consideramos que es necesario formular un criterio de unificación que permita identificar dónde deben situarse, en una política criminal con retorno a los principios, los conceptos de inte-

54 Ibidem, pp. 24, 77 y 78.

55 En este sentido, "la muerte prevista como efecto colateral solo será culpable cuando el agente carezca de una razón proporcionadamente grave para causarlo o impedirlo. A la inversa, si el agente cuenta con dicha razón proporcionada, la muerte prevista como efecto colateral está justificada. Esto es lo que establece el clásico principio del doble efecto, que funda la distinción entre aborto directo y aborto indirecto, y permite dar solución justa a los casos de embarazos riesgosos para la vida de la madre"; Miranda Montecinos, Alejandro, "La injusticia del aborto procurado", en Aguirrezabal, M. y Bertelsen, S. (eds.), El aborto. Perspectivas filosófica, jurídica y médica, Cuadernos de extensión jurídica 27, Santiago, Universidad de los Andes, 2015, p. 43. 
UNIVERSOS ÉTICOS Y LA METARREGLA DEL DOBLE...

rés, mal, bien jurídico y efecto colateral. A analizar esta idea dedicaremos las páginas que siguen.

\section{UNIVERSOS ÉTICOS Y LA METARREGLA DEL DOBLE EFECTO}

Independientemente de cómo se hayan creado estos universos éticos, cuando existe una evolución histórico-dogmática, se da el fenómeno de su aparición en situaciones trágicas y de conflicto vital en el estado de necesidad. Es decir, que encontramos en su estudio configuraciones propias de alguna tradición filosófica, ya sea kantiana, consecuencialista, teleológica o meramente proporcionalista, a partir de las cuales se intentan justificar las diversas soluciones. Si tenemos a la vista el problema del mal, por mucho que difieran estos universos en torno a qué es el mal, existen ciertas premisas que permanecen invariables en la ponderación, que son las que hacen posible que el cálculo sea o no arbitrario, según el caso. Precisamente, dicho cálculo traerá la arbitrariedad, al punto que la identificación de estos universos se vuelva tan difusa que no sea posible determinar la premisa desde la cual parten.

De la misma forma, en los sistemas consecuencialistas no se observa la existencia de absolutos morales, porque parecieran ser parte - desde sus postulados- de una moral perfeccionista que rigidiza en exceso la ponderación de intereses. Y, de la misma manera, representan en consecuencia una fractura con el pensamiento científico. Así, el consecuencialismo se centra - principalmenteen una ponderación de bienes físicos, en contraposición a una moral absolutista. Para el primer modelo sería posible ponderar vidas humanas, y en la segunda estaría siempre prohibido. Así las cosas, en la filosofía política contemporánea se designan a estas posiciones como "dos universos éticos". ${ }^{56}$ En la literatura, usualmente se da la confrontación de estas dos tradiciones filosóficas en la ponderación de vidas humanas. ${ }^{57}$

56 Bobbio, Norberto, Teoría general de la política, trad. de Antonio de Cabo y Gerardo Pisarello, Madrid, Trotta, 2003, p. 253.

57 Chiesa, Luis E., “Caso La Mignonette”, en Sánchez-Ostiz Gutiérrez, Pablo 
Asimismo, en la dogmática penal chilena es posible observar este contraste entre el principio neccesitas legem non habet y el consecuencialismo formalista. ${ }^{58}$ Sin embargo, el principio moral absolutista del doble efecto permitiría ponderar vidas humanas. Principio que, si bien admite la prohibición de que nunca es lícito cometer un homicidio en contra de seres humanos inocentes (occisión directa), acepta su ponderación siempre que, en la situación de estado de necesidad, la muerte sea un efecto colateral (occisión indirecta) de la acción del agente que realiza un acto lícito.

La muerte de los inocentes nunca puede ser intentada directamente, porque de lo contrario estaríamos utilizando al ser humano como un medio. Así, García Huidobro y Miranda, en atención al principio en cuestión - en relación con la sentencia del Tribunal Constitucional alemán de la Ley de Seguridad Aérea-, han sostenido que, en ningún caso, en la destrucción de una aeronave secuestrada por terroristas, transformada en un misil, "se está eligiendo, ni como fin ni como medio, la muerte de los inocentes, sino simplemente el rechazo de la agresión". ${ }^{59}$ Pues bien, "el rechazo de la agresión se produce no porque los inocentes mueran sino a pesar de que ellos mueran. Lo que directamente se está haciendo no es, per se, matarlos, sino un acto distinto, aunque de hecho ellos mueran". ${ }^{60}$ Por ello, saber que se mata a inocentes como efecto colateral es matar. Sin embargo, dicho efecto no es constitutivo de homicidio.

Ahora bien, Hörnle no observa —en este tipo de razonamientos del doble efecto- grandes diferencias en lo que concierne a la destrucción de aviones secuestrados por terroristas, con el conse-

(coord.), Casos que hicieron doctrina en derecho penal, 2a. ed., Madrid, La Ley, 2011, pp. 99-103.

58 Wilenmann, Javier, "El fundamento del estado de necesidad justificante en el derecho penal chileno. Al mismo tiempo, introducción al problema de la dogmática del estado de necesidad en Chile", Revista de Derecho (Valdivia), vol. XXVII, núm. 1, 2014, pp. 224-226, disponible en: http://mingaonline.uach.cl/pdf/revider/v27n1/ art10.pdf.

59 García-Huidobro, Joaquín y Miranda Montecinos, Alejandro, "Sobre la licitud de la destrucción de una aeronave agresora que lleva pasajeros inocentes", Revista de Derecho Universidad Católica del Norte, año 20, núm. 2, 2013, p. 356.

60 Idem. 
UNIVERSOS ÉTICOS Y LA METARREGLA DEL DOBLE...

cuencialismo, porque llegan a los mismos resultados, "puesto que en caso de homicidio no intencional, el marco es... el... consecuencialista... sin que [el principio] añada nada nuevo". ${ }^{61}$ Sin embargo, la autora reconoce que en el caso de algunos de sus representantes, como Kamm, Quinn, Foot, entre otros, su planteamiento no puede ser reconducido a un utilitarismo tosco de ponderación entre vidas humanas. ${ }^{62}$

Por otra parte, otros consecuencialistas - como Singer- han sostenido que, a propósito del tratamiento paliativo de enfermedades terminales, en el principio de doble efecto "la diferencia entre no dar el tratamiento necesario para prolongar la vida y poner una inyección letal reside en la intención con que se realizan ambas acciones". ${ }^{63}$ Pues bien, para el autor, los partidarios del doble efecto, "argumentan que en tanto en cuanto el efecto directamente intencionado sea el beneficioso y no viole una norma moral absoluta, la acción es permisible". ${ }^{4}$ Por ello, "la distinción entre un efecto directamente intencionado y un efecto secundario es artificial", ${ }^{65}$ porque "no podemos evitar la responsabilidad dirigiendo simplemente nuestra intención hacia un efecto en lugar de otro".66 Pues bien, "si prevemos ambos efectos, debemos aceptar la responsabilidad de los efectos previsibles de lo que hacemos". ${ }^{67}$

Si bien la crítica de Singer puede tener acogida en principio en materia jurídico-penal, diferenciándose de la de Hörnle, en la denuncia directa de un encubrimiento del consecuencialismo debemos indicar que el principio sólo se aplica en situaciones excepcionales en las que el agente se ve enfrentado a la posibilidad de terminar indirectamente con la vida de inocentes. Es, en consecuencia, un prin-

61 Hörnle, Tatjana, "Matar para salvar muchas vidas. Casos difíciles de estado de necesidad desde la perspectiva filosófico-moral y jurídico-penal”, InDret, Revista para el Análisis del Derecho, núm. 2, p. 11, disponible en: http://www.indret.com/ pdf/744_es.pdf.

62 Hörnle, Tatjana, op. cit., p. 7, nota 12, y p. 8, nota 16.

63 Singer, Peter, Ética práctica, Akal, Madrid-España, 2009, p. 212.

64 Idem.

65 Idem.

66 Idem. Énfasis añadido.

67 Idem. 
cipio que no tiene pretensiones generales de aplicación en materia jurídico-penal.

Ahora bien, en respuesta a estas críticas, el doble efecto reconoce que, en la atribución de responsabilidad penal, existen formas análogas de homicidio. Estas formas se denominan situaciones de occisión indirecta sin causa proporcionada que son de dos tipos:

...en primer lugar, aquellas en las que el agente realiza una acción ilícita previendo con certeza moral que de ella se seguirá la muerte de una persona (como en el caso del sujeto que, para defraudar una compañía de seguros, hace explotar el avión asegurado mientras éste se encuentra en vuelo) y, en segundo lugar, aquellas en las que el agente realiza una acción de suyo lícita pero que se ordena a un bien que no guarda proporción con la muerte que se sigue como efecto de ella (como en el caso... de la mujer embarazada que, para ganar a un concurso de belleza, se somete a una cirugía estética que con certeza o con un alto grado de probabilidad provocará la muerte del feto). ${ }^{68}$

Desde luego, esta perspectiva no está exenta de dificultades. Éstas se generan, sobre todo, cuando se observan en una occisión indirecta - sin causa proporcionada - una forma análoga de homicidio, porque nos reconduce a una noción de dolo que parte de la realización intencionada del tipo. Es decir, que nos lleva a la teoría de la voluntad en materia penal. Sin embargo, ésta sostiene, en los delitos de mera actividad, en los cuales la sola realización de la conducta es constitutiva del ilícito, "la existencia de un delito doloso en caso de mero conocimiento de las circunstancias típicas". ${ }^{9}$ Por otra parte, en delitos de resultado - como el homicidio- cabe preguntarnos si sería válido este tipo de razonamiento: ¿acaso un magistrado negaría el dolo del sujeto que hace explotar un avión asegurado en vuelo (lleno de pasajeros) porque afirma que su intención es defraudar a la compañía de seguros y no matar a los pasajeros? La única razón de que exista una forma análoga de homicidio es considerar que la

68 Miranda Montecinos, Alejandro, El principio del doble efecto, cit., pp. 373 y 374.

69 Ragués I. Vallès, Ramón, “Consideraciones sobre la prueba del dolo”, Revista de Estudios de la Justicia, núm. 4, 2004, p. 15, disponible en: http://web.derecho.uchi le.cl/cej/recej/recej4/archivos/PRUEBA\%20DEL\%20DOLO\%20RAGUES\%20_8_.pdf. 
UNIVERSOS ÉTICOS Y LA METARREGLA DEL DOBLE...

muerte de los inocentes no es voluntaria, es decir, "objeto de la voluntad del agente". ${ }^{70}$

Pues bien, nos parece que caben fundadas dudas sobre si el sujeto obra dolosamente, al representarse los elementos objetivos requeridos por el tipo. Podría ser suficiente "obrar con conocimiento del riesgo concreto de producción del resultado". ${ }^{71}$ De ahí que, siguiendo la diferenciación entre efecto directo e indirecto o colateral, si se contempla la muerte como una consecuencia probable de un acto prohibido, no observamos una diferencia sustancial. De esta manera, si el agente intenta disparar a A y se puede percatar que B está muy cerca de él - a un metro de distancia- conociendo el alcance del arma, puede estimar como un efecto directo de su acción el matar a B. Ello, aunque en su intento por matar a A hubiera pensado que era poco probable la muerte de B. Aquí, si bien el agente no desea la muerte de B y no la contempla como un medio o fin, se da un homicidio doloso, porque se representa — según su conocimientocomo probable el resultado. ${ }^{72}$

Por todo lo expuesto, a partir de la intención no puede construirse una noción del dolo que sea válida para todo el sistema jurídicopenal. ${ }^{73}$ Por consiguiente, obrar con conocimiento del riesgo de

70 Miranda Montecinos, Alejandro, El principio del doble efecto, cit., p. 374.

71 Ragués I. Vallès, Ramón, op. cit., p. 15.

72 En este contexto, debemos realizar el análisis desde los parámetros del hombre. Si bien existen diversas concepciones jurídico-penales en torno al grado de conocimiento que se requiere para estar en presencia de un comportamiento doloso, nos parece sensato "enjuiciar la situación según lo haría un hombre medio con sus conocimientos y con los que personalmente pudiera tener el agente", Mir Puig, Santiago, Derecho penal. Parte general, 9a. ed., Barcelona, Reppertor, 2011, p. 474.

${ }^{73}$ En este contexto, una parte de la doctrina se ha esforzado recientemente en la elaboración de un concepto unitario de dolo. Es decir, una noción que considere todos los casos que deben comprenderse en la definición y que establezca una delimitación precisa respecto de la imprudencia. Esto ha dado espacio a propuestas con diversos grados de normativización que son alternativas frente a las tradicionales. Así, se sostiene que "lo específico del dolo frente a la imprudencia es, pues, que el sujeto que actúa dolosamente conoce el significado típico de la conducta que realiza voluntariamente y el sujeto imprudente desconoce en toda su dimensión ese significado"; Silva Sánchez, Jesús María, Aproximación al derecho penal contemporáneo, Barcelona, Bosch, 1992, p. 401. 
matar a un inocente es un comportamiento que se reputa siempre voluntario, ${ }^{74}$ salvo que, en la valoración del hecho conforme a la norma, estemos en presencia de una causal de justificación que permita ponderar los efectos de la acción (directo y colateral). Los problemas se plantean en precisar qué grado de proporción se requiere entre los efectos ponderados y el grado de control de los mismos. ${ }^{75}$ De ahí que desde una perspectiva radical del doble efecto, únicamente serían punibles los daños colaterales a civiles producidos con dolo directo de primer grado en consonancia con los móviles de la acción, siendo excluidos los generados con dolo directo de segundo grado y dolo eventual. ${ }^{76}$

En otras palabras, la intención para el doble efecto es un "criterio para distinguir entre (i) el efecto [directo] que constituye el acto mismo y (ii) sus restantes consecuencias [efecto colateral]". ${ }^{77}$ Por eso, aunque nos parezca que el criterio de distinción es de orden primariamente objetivo, igualmente se podrá indicar que el grado de conocimiento del agente es importante en torno a la certeza de las consecuencias de la acción. Y, por lo mismo, una manifestación de voluntad del imputado se admite como un elemento más en la selección de los medios en el proceso penal. ${ }^{78}$ Sin embargo, ésta es

74 Respecto de esta interpretación en la dogmática nacional en torno al inciso segundo del artículo 1o. del Código Penal chileno, véase Hernández, Héctor, “Comentario al artículo 1o. del Código Penal”, en Couso Salas, J y Hernández Basualto, H. (dirs.), Código Penal comentado. Parte general. Doctrina y jurisprudencia, Santiago, Abeledo Perrot-Legal Publishing, 2011, pp. 14 y 15.

75 En este contexto, se observa este fenómeno en el modelo inglés, en atención a la importancia de la diferenciación entre querer (will) e intentar (intend), en Austin, John, Lectures on Jurisprudence or the Philosophy of Positive Law, London, J. Murray, 1880 , p. 206 y p. 212.

76 Ohlin, JD, "Targeting and the Concept of Intent", Michigan Journal of International Law, núm. 35, 2013, pp. 79 y ss. Asimismo, se observa un análisis crítica a esta perspectiva radical del doble efecto en Silva Sánchez, Jesús María, "Asesinatos selectivos en la "guerra punitiva» contra el terrorismo", InDret, núm. 1, 2017, p. 6, nota 19.

77 Miranda Montecinos, Alejandro, El principio del doble efecto, cit., p. 151.

78 Nos parece que captar toda la complejidad de la intención es imposible. Pues bien, empíricamente el agente es un sistema autorreferencial que, en contacto consigo mismo, toma una u otra decisión. Por ello, el sistema jurídico-penal interpreta 
UNIVERSOS ÉTICOS Y LA METARREGLA DEL DOBLE...

prescindible en la valoración jurídico-penal. Es decir, que se puede aplicar o rechazar la justificante con independencia de saber cuál es exactamente el propósito del agente. ${ }^{79}$ Por ello, proponemos denominar la intención como el conocimiento cierto de los efectos de la acción.

La razón de tal denominación (conocimiento cierto de los efectos de la acción) radica en que es posible que una especie física se ordene a diversos fines de la voluntad. Sin embargo, en esta especie radica la preponderancia del análisis jurídico-penal. Así, a modo de ejemplo, en caso de matar a un hombre, la acción se puede dirigir a la legítima defensa, el estado de necesidad o la perpetración de un homicidio. Pues bien, la subsistencia de alguno de estos tipos depende del examen de la concurrencia de sus elementos en atención a los requerimientos del ordenamiento jurídico.

Si bien estos actos típicos son de diferente especie moral $l^{80}$-la legítima defensa, el estado de necesidad y el homicidio- según la naturaleza del doble efecto, porque los primeros se encuentran justificados (acto de virtud) y el último sancionado (acto de vicio), son las condiciones de cada uno de estos tipos lo que permite determinar la multiplicidad de fines a los que el acto se ordena. En esta línea, si un sujeto controla la situación y provoca la muerte de otro, está dentro de los parámetros de la imputación fáctica. Sin embargo, en el juicio de valoración del hecho conforme a la norma se examinará si concurren los presupuestos de la legítima defensa (artículo 10, número 4, del Código Penal) o el estado de necesidad (artículo 10, número 11). De lo contrario, subsiste el tipo de

estas decisiones en uno u otro sentido según la reglas del sistema jurídico-penal. En otras palabras, la realidad del agente está configurada en el sistema en atención a la operación recursiva de sus propios cálculos, y la realidad no es más que la reproducción de ésta en dichos términos; véase Luhmann, Niklas, Sociología del riesgo, trad. Silvia Pappe, Brunhilde Erker y Luis Felipe Segura, 3a. ed., México, Universidad Iberoamericana, 2006, pp. 14 y ss.

79 En este contexto, en el sistema procesal chileno existe el derecho a guardar silencio. Pues bien, tanto la defensa como la fiscalía deberán presentar cada uno de los elementos que sustenten de mejor manera su teoría del caso.

80 En este contexto, respecto de la distinción original entre especie moral y física del acto humano según los parámetros tomistas, véase Miranda Montecinos, Alejandro, El principio del doble efecto, cit., pp. 132-136. 
homicidio (artículo 391, número 2, del Código Penal), y, posteriormente, en una imputación de segundo orden o jurídica se analizará si es o no exigible ajustar al sujeto su comportamiento a la norma en conocimiento de la infracción.

Pasemos ahora a lo más difícil, que es determinar si es posible, en el caso de quien se ve enfrentado a la decisión de matar a un inocente para salvar su propia vida, la de terceros o de un mayor número de personas, excluir la posibilidad de discernir entre efectos directos e indirectos en la ecuación. Es indudable que, de los problemas teóricos que suscita el principio, el concepto de intención es el punto más complejo en su aplicación. Pues bien, algunos autores, como Finnis, entre otros, dan lugar —en términos jurídicopenales- a una excesiva subjetivización de la intención. De ahí que adquiera relevancia la crítica singeriana de que el principio sólo con dirigir "nuestra intención hacia un efecto en lugar de otro" permite evadir la responsabilidad.

Expongamos, con un caso clásico de la filosofía moral, a qué nos referimos con una lectura excesivamente subjetiva de la intención, o también denominada "noción estricta de intención". ${ }^{11}$ Podemos considerar un grupo de exploradores que han ingresado a una caverna. Inesperadamente, uno de los exploradores queda atrapado en la única salida de la caverna por su obesidad. Luego, el nivel del agua en el interior de la caverna comienza a subir. Nuestros exploradores deliberan cómo salir, y consideran que la única alternativa es dinamitar al compañero atrapado en la salida de la caverna. ${ }^{82}$

Ciertamente, un sector dominante de la doctrina del doble efecto convendría en que dinamitar al explorador obeso sería una occisión directa, es decir, constitutiva de homicidio, con independencia de la discusión jurídica en torno a la inexigibilidad de otra conducta. En efecto, los exploradores terminarían directamente con la vida del

81 Miranda Montecinos, Alejandro, "La noción de intención y el principio del doble efecto una controversia sobre el razonamiento práctico y descripción de acciones humanas", en Corso de Estrada, L. E. et al. (eds.), Ley y razón práctica en el pensamiento medieval y renacentista, Pamplona, Eunsa, 2014, p. 119.

${ }^{82}$ El ejemplo de los exploradores atrapados en la caverna es de la autoría de Philippa Foot. 
UNIVERSOS ÉTICOS Y LA METARREGLA DEL DOBLE...

que se encuentra en la salida de la caverna. Sin embargo, otros, como Finnis, Grisez y Boyle, retornando a la interpretación del requisito en que el efecto malo de la acción no puede ser elegido como medio para alcanzar el efecto bueno, considerarían que la muerte del explorador es un efecto colateral, porque el propósito de los exploradores es disolver al atrapado en partículas con objeto de liberar la salida.

Este último razonamiento da razones a la dogmática penal para afirmar que la noción del dolo de las consecuencias seguras impide la aplicación del doble efecto. En efecto, Finnis, Grisez y Boyle pretenden generar un quiebre en la identificación de la noción de medio (propia del orden moral) con la noción de causa (atingente al orden físico).$^{83}$ Así, consideran que la tradición del principio se centró en las relaciones de causa-efecto - reconocibles por un observador externo- antes de definir el objeto preciso de la elección del agente. Pero, ciertamente, si aceptamos esta interpretación habría que reconocer que la intención directa de matar al explorador atrapado en la salida de la caverna no concurriría. De la misma forma que sería posible afirmar en el caso de la craneotomía, cuando se aplasta el cráneo de un niño vivo - en razón de una desproporción céfalopélvica- por haber quedado atrapado en el canal de parto, que "la muerte del bebé [sería] un efecto colateral de cambiar las dimensiones de su cráneo". ${ }^{84}$

Ahora bien, de aceptar como correcto este planteamiento sería razonable excluir de la dogmática penal el principio del doble efecto. Sin embargo, consideramos que esta interpretación no es adecuada, porque la estrategia de argumentación racional del principio es consonante con un criterio que entrega parámetros objetivo-subjetivos en la ponderación de intereses en situaciones trágicas de estado de necesidad. Es decir, que limita la aplicación desmesurada del estado de necesidad defensivo ante la indeterminación semántica del con-

${ }^{83}$ Miranda Montecinos, Alejandro, "La noción de intención y el principio del doble efecto una controversia sobre el razonamiento práctico y descripción de acciones humanas", en Corso de Estrada, L. E. et al. (eds.), Ley y razón práctica en el pensamiento medieval y renacentista, Pamplona, Eunsa, 2014, p. 117; Finnis, J. et al., "«Direct» and «Indirect»: a Reply to Critics of our Action Theory", The Thomist, núm. 65, 2001, pp. 19 y 20.

84 Finnis, J. et al., op. cit., p. 32. 
cepto peligro. Conforme con ello, nos parece que aun en atención a "la extensión del dolo en materia penal, que abarca siempre las consecuencias necesarias aunque no queridas de un acto", ${ }^{85}$ es aventurado afirmar que "el potencial explicativo [del principio del doble efecto] es menor", ${ }^{86}$ porque el dolo es un elemento que da sentido a la acción que, con independencia a las motivaciones puramente psicológicas o internas del agente, está en correlación a los presupuestos fácticos de la misma. ${ }^{87}$ Así, el conocimiento de los efectos de una acción está vinculado con el conocimiento de las naturalezas. Pues bien, a modo de ejemplo, en el caso del explorador atrapado en la caverna, la explosión va a producir un efecto que el agente conoce como cierto, no sólo por la vía de la razón, sino también por causa de su conciencia individual, que puede proyectar y compartir las experiencias. Al conocer su propio cuerpo, puede imaginar lo que va a pasar con el otro cuando explote.

La interpretación del sentido de la acción, en atención al contexto en que tiene lugar, está supeditada a las pruebas que se presenten en el proceso penal. Así, en atención a las circunstancias concretas de la situación de peligro, la prueba presentada en el proceso y la positivización del concepto normativo de mal hacen posible indicar —con alguno de los correctivos enunciados y los parámetros dominantes en la tradición del doble efecto- que los efectos colaterales tengan espacio en este tipo de situaciones.

Nos parece que el concepto jurídico indeterminado de mal en el estado de necesidad requiere del doble efecto. Sin embargo, es necesario que su aplicación acepte el dolo como conocimiento. De este modo, el doble efecto procurará definir con precisión ciertas reglas de delimitación en la justificación. Y probablemente respecto de esta problemática esté en lo cierto, porque no deforma el estado de necesidad defensivo o agresivo a través del concepto de peligro, y es una regla especialmente pensada para casos en los que colateralmente la muerte se encuentra justificada. Es decir, que no se beneficia de la

85 Wilenmann, Javier, “Imponderabilidad de la vida humana...”, cit., p. 122, nota 38.

86 Idem.

87 Oxman, Nicolás, “Una aproximación al sistema de imputación subjetiva en el derecho penal anglosajón”, Revista Ius et Praxis, año 19, núm. 1, 2013, p. 152, disponible en: http://www.scielo.cl/pdf/iusetp/v19n1/art05.pdf. 
UNIVERSOS ÉTICOS Y LA METARREGLA DEL DOBLE...

"indeterminación semántica" ${ }^{88}$ del origen del peligro —en la esfera del destinatario- para determinar si se justifica o no la acción. Un claro ejemplo, tratado en la sección anterior, se deriva en casos de aborto o eutanasia indirecta, porque no atribuye forzosamente responsabilidad a los involucrados como se pretende por algunos autores en el estado de necesidad defensivo.

Así las cosas, nos parece que el doble efecto no puede ser incorporado dentro del consecuencialismo, ${ }^{89}$ porque éste requiere de dos etapas que el principio no está dispuesto a relativizar. La primera es definir qué se entiende por bueno, y la segunda consiste en determinar cómo maximizar lo bueno. De este modo, todo depende de cómo se defina lo bueno. ${ }^{90} \mathrm{Si}$ bien una postura consecuencialista podría considerar la importancia de la dignidad humana en una situación de peligro, dicha premisa es virtualmente absoluta en lo que concierne a la imposibilidad de terminar directamente con la vida de un inocente.

En síntesis, el problema que presentan ciertos razonamientos consecuencialistas no proviene de la selección del mal menor, sino de un análisis meramente técnico de las situaciones de estado de necesidad, en el cual se contemple únicamente la ponderación de bienes físicos como la propiedad, la salud, la vida, entre otros, sin considerar exigencia deóntica alguna. El consecuencialismo distingue entre bienes de orden moral y premoral, físicos u ónticos. En los bienes de orden moral encontramos la prohibición absoluta de matar directamente a un inocente, la justicia, la prudencia, entre otros principios. En cambio, en los bienes premorales están los bienes físicos inmediatos, como la salud, la propiedad, la integridad física, etcétera, plano en el cual se determina si la conducta se encuentra ajustada a la regla de comportamiento. El peligro de esta posición está en insertar la ponderación sólo en el campo de los bienes físicos.

88 Wilenmann, Javier, “Imponderabilidad de la vida humana..., cit., p. 36.

89 Sin embargo, existe una mirada proporcionalista del principio; véase Miranda Montecinos, Alejandro, El principio del doble efecto, cit., pp. 90-97.

90 Por ello, una posición consecuencialista se podría diferenciar del utilitarismo al adoptar premisas que difieran de la máxima bienestarista, con independencia del bienestar que implica para la mayoría o la sociedad la decisión de terminar con la vida de un menor número de inocentes en una situación de necesidad. 


\section{REFLEXIONES FINALES}

El análisis del estado de necesidad del artículo 10, número 11, en lo relativo a situaciones de conflicto vital, requiere reconocer la presencia de dos universos éticos. Su estudio exige realizar un examen filosófico-dogmático de delimitación en casos de estado de necesidad. Por tanto, definir las premisas de estos universos permite entregar un contexto que facilite precisar sus implicancias en la resolución de este tipo de casos. Tras este análisis filosófico-dogmático, en el sistema jurídico penal chileno se abre un espectro complejo, porque la falta de claridad se reconduce a una posición (en apariencia) axiológicamente neutra.

En la primera sección trazamos una diferencia entre las nociones de "mal" e "interés", a partir de la cual es posible estructurar el estudio de los universos éticos presentes en el estado de necesidad. Esta perspectiva puede ayudar a formular tanto el panorama dogmáticogeneral en torno a la materia como la propuesta de un modelo interpretativo que logre identificar sus subelementos: interés, bien jurídico o efecto colateral, entre otros.

La distinción entre mal e interés se puede advertir en el contraste entre la institución del estado de necesidad en el derecho chileno, y en el alemán - en lo que concierne a la ponderación-. El estado de necesidad chileno y alemán supone una ponderación de males que, ante la misma situación de peligro real, debe cumplir con los requisitos de proporcionalidad y subsidiariedad, requisitos que no pueden ser desvinculados en situación de conflicto vital de una premisa mayor: la prohibición de matar directamente a un inocente.

La ponderación de los efectos en el principio del doble efecto, conforme a las categorías que hemos utilizado en esta investigación, permite sostener que su aplicación es posible en situaciones de estado de necesidad. Este principio no admitiría realizar concesiones con el consecuencialismo. Asimismo, el grado de objetivización de la intención que presenta, en contraposición a los planteamientos de Finnis, Grisez y Boyle, permite enfrentar las críticas en torno al dolo de las consecuencias seguras. El principio acepta la existencia 
UNIVERSOS ÉTICOS Y LA METARREGLA DEL DOBLE...

de efectos colaterales que, aunque terminen con la vida de inocentes, no implican un quiebre con el principio de la dignidad humana. La ponderación entre los efectos directos o indirectos, concernientes al principio en cuestión, no pueden ser aislados de la aplicación del principio del interés preponderante.

El doble efecto sólo comprende casos excepcionales de estado de necesidad, por lo que no es posible observar una interacción que perturbe la posibilidad de atribuir responsabilidad por un homicidio con base en el conocimiento. Por ello, el principio puede tener lugar en la interpretación del estado de necesidad, e incluso en la dogmática existe un sector que, con la formulación del artículo 10, número 11, y la antigua regulación del artículo 119 del Código Sanitario, reserva un espacio para su aplicación en casos de estado de necesidad en los cuales se vea afectada la vida de inocentes.

Por otro lado, la relación entre doble efecto y consecuencialismo, como ha sido utilizada por un sector de la doctrina, es de tal superficialidad que muchos, si bien la consideran equivalente en sus resultados al consecuencialismo, desconocen las diferencias sustanciales que pueden tener en la resolución de situaciones trágicas de estado de necesidad. El estado de necesidad es toda situación de conflicto de intereses ante una situación de peligro actual o inminente, mientras que el doble efecto es una metarregla que desconoce el dogma de la imponderabilidad de la vida humana, y acepta su ponderación en situaciones de peligro por efecto colateral. El no caer en el dogma de la imponderabilidad de la vida humana le permite ponderar los efectos involucrados. Dicho con otras palabras, los números cuentan, pero deben ser considerados en atención a la imposibilidad de terminar directamente con la vida de un tercero, y aceptar sólo por efecto colateral dicho resultado, resultado que debe tener origen en una acción licita necesaria y proporcionada.

Finalmente, el sólo utilizar la proporcionalidad para resolver un caso de estado de necesidad implicaría dar una respuesta parcial al problema. Su complejidad requiere de la consideración de todos los factores concurrentes, representados por tres principios esenciales: el principio de legalidad, el principio de seguridad y el principio de respeto a la dignidad humana. No obstante, esta política también considera dentro de sus metarreglas un plano de de- 
limitación para impedir la lesión del núcleo esencial de la dignidad humana. A partir de todo lo anterior, en consecuencia, parece razonable repensar los parámetros de aplicación del doble efecto en la dogmática penal.

\section{BIBLIOGRAFÍA}

Alessandri R., Arturo, Tratado de derecho civil. Partes preliminary general, 7a. ed., Santiago, Editorial Jurídica de Chile, 2005, t. I.

Austin, John, Lectures on Jurisprudence or the Philosophy of Positive Law, London, J. Murray, 1880.

BAldó LAVIlla, Francisco, Estado de necesidad y legítima defensa: Un estudio sobre las «situaciones de necesidad» de las que derivan facultades y deberes de salvaguarda, Barcelona, Bosch, 1994.

BARros Bourie, Enrique, Tratado de responsabilidad extracontractual, Santiago, Editorial Jurídica de Chile, 2006.

BASCuÑán, Antonio, "La píldora del día después ante la jurisprudencia”, Revista de Estudios Públicos, núm. 95, 2004, disponible en: https://www.cepchile.cl/la-pildora-del-dia-despues-antela jurisprudencia/cep/2016-03-04/093409.html.

Bertelsen, Simonetti, Soledad y García Palominos, Gonzalo, "La protección del derecho a la vida y el estatuto del no nacido en el sistema interamericano de derechos humanos", en Aguirrebazábal, M. y Bertelsen, S. (ed.), El aborto. Perspectiva filosófica, jurídica y médica, Cuadernos de extensión jurídica, núm. 27, Santiago, Universidad de los Andes, 2015.

Boвbio, Norberto, Teoría general de la política, trad. de Antonio de Cabo y Gerardo Pisarello, Madrid, Trotta, 2003.

CAndano Pérez, Mabel y Guerra Espinosa, Rodrigo, "Responsabilidad penal médica: consideraciones en la aplicación del principio del doble efecto", Rev.Med.Electrón, vol. 40, núm. 4, 2018. 
ChiesA, Luis E., “Caso La Mignonette”, en SÁnchez-Ostiz GutiérRez, Pablo (coord.), Casos que hicieron doctrina en derecho penal, 2a. ed., Madrid, La Ley, 2011.

Cousiño Mac IVER, Luis, Derecho penal chileno. Parte general, Santiago, Editorial Jurídica de Chile, 1979, t. II.

Cury, Enrique, Derecho penal. Parte general, 7a. ed., Santiago, Ediciones Universidad Católica de Chile, 2005.

ETcheberry Orthusteguy, Alfredo, Derecho penal, 3a. ed., Santiago, Editorial Jurídica de Chile, 1998, t. I.

FInNIS, J. et al., "«Direct» and «Indirect»: a Reply to Critics of our Action Theory", The Thomist, núm. 65, 2001.

FinNis, John, Natural Law and Natural Rights, Oxford, Clarendon Press, 1993.

Fuentes, Dánae, La ponderación de los males en el estado de necesidad, Santiago, Legal Publishing, 2009.

García-Huidobro, Joaquín y Miranda Montecinos, Alejandro, "Sobre la licitud de la destrucción de una aeronave agresora que lleva pasajeros inocentes", Revista de Derecho Universidad Católica del Norte, año 20, núm. 2, 2013.

Greenawalt, Kent, "Distinguishing Justifications from Excuses", Law \& Contemporary Problems, vol. 49, núm. 3, 1986, disponible en: http://scholarship.law.duke.edu/cgi/viewcontent. cgi? article $=3860 \&$ context $=$ lcp.

GuERra EsPINOSA, Rodrigo Andrés, "Ambivalencia en el principio del interés preponderante", Revista de Derecho de la Pontificia Universidad Católica de Valparaíso, 2017, núm. 49, disponible en: http://dx.doi.org/10.4067/S0718-68512017000200187.

Guerra Espinosa, Rodrigo, "Principio de no contradicción en el estado de necesidad", Revista de Derecho (Valdivia), vol. 30, núm. 2, 2017, disponible en: http://dx.doi.org/10.4067/S07 18-09502017000200016.

GuERra Espinosa, Rodrigo, Estado de necesidad como conflicto de intereses: una propuesta de interpretación desde la inevitabilidad, Santiago-Chile, Ara Editores, 2017. 
Gur-Arye, Miriam, “ ¿Should a Criminal Code Distinguish Between Justification and Excuse?", Canadian Journal of Law and Jurisprudence, vol. V, núm. 2, 1992, disponible en: http://heinon line.org/HOL/Page?handle=hein.journals/caljp5\&div=20\&g_ sent=1\&collection=journals\#217.

Hernández, Héctor, "Comentario al artículo 1o. del Código Penal", en Couso Salas, J y Hernández Basualto, H. (dirs.), Código Penal comentado. Parte general. Doctrina y jurisprudencia, Santiago, Abeledo Perrot-Legal Publishing, 2011.

HöRnLE, Tatjana, "Matar para salvar muchas vidas. Casos difíciles de estado de necesidad desde la perspectiva filosófico-moral y jurídico-penal", Indret, Revista para el Análisis del Derecho, disponible en: http://www.indret.com/pdf/744_es.pdf.

HRUSCHKA, Joachim, Imputación y derecho penal. Estudios sobre la teoría de la imputación, 2a. ed., Buenos Aires, Editorial B de F, 2009.

Horvitz Lennon, María Inés y Soto Piñeiro, Miguel, “Consideraciones críticas sobre la regulación del delito de aborto en el anteproyecto de nuevo código penal elaborado por el foro del Ministerio de Justicia", Revista de Estudios de la Justicia, núm. 9, 2007.

LENCKNER, Theodor, Der rechtfertigende Notstand. Zur Problematik der Notstandregelung im Entwurf eines Strafgesetzbuches, Tübingen, Mohr Siebeck, 1965.

Luhmann, Niklas, Sociología del riesgo, 3a. ed., trad. de Silvia Pappe, Brunhilde Erker y Luis Felipe Segura, México, Universidad Iberoamericana, 2006.

MAÑALICH, Juan Pablo, "El estado de necesidad exculpante. Una propuesta de interpretación del artículo 10 núm. 11 del Código Penal Chileno", en VAn WeEzel, A. (ed.), Humanizar y renovar el derecho penal. Estudios en memoria de Enrique Cury, Santiago, Legal Publishing, 2013.

MaÑALICH, Juan Pablo, "Normas permisivas y deberes de tolerancia”, en MAÑALICH, J. P. (coord.), La antijuricidad en el derecho 
UNIVERSOS ÉTICOS Y LA METARREGLA DEL DOBLE...

penal. Estudios sobre las normas permisivas y la legítima defensa, Montevideo-Buenos Aires, Editorial B de F, 2013.

MaRTínez CANTón, Silvia, La ponderación en el estado de necesidad, León, Universidad de León, Secretariado de Publicaciones, 2006.

McCoRmick, Richard, "Ambiguity in Moral Choice", en McCormick, R y Ramsey, P. (eds.), Doing Evil to Achieve Good. Moral Choice in Conflicts Situations, Chicago-Illinois, Loyola University Press, 1978.

McCormick, Richard, "El principio del doble efecto", trad. de A. Goñi, Concilium 120, 1976.

Mir PuIG, Santiago, Derecho penal. Parte general, 9a. ed., Barcelona, Reppertor, 2011.

Miranda Montecinos, Alejandro, "Consequentialism, the Action/ Omission Distinction, and the Principle of Double Effect: Three Rival Criteria to Solve Vital Conflicts in Cases of Necessity", The American Journal of Jurisprudence, vol. 62, núm. 2, 2017, disponible en: file:///c:/users/profesor2/downloads/ amm_consequentialism $\% 252 c \% 20$ action-omission $\% 20$ and\%20double\%20effect.pdf.

Miranda Montecinos, Alejandro, "El principio del doble efecto y su relevancia en el razonamiento jurídico", Revista Chilena de Derecho, vol. 35, núm. 3, 2008, disponible en: http://www.scielo. cl/scielo.php?pid=S0718-34372008000300005\&script $=$ sci_ arttext.

Miranda Montecinos, Alejandro, "La injusticia del aborto procurado”, en Aguirrezabal, M. y Bertelsen, S. (eds.), El aborto Perspectivas filosófica, jurídica y médica, Cuadernos de extensión jurídica 27, Santiago, Universidad de los Andes, 2015.

Miranda Montecinos, Alejandro, "La noción de intención y el principio del doble efecto una controversia sobre el razonamiento práctico y descripción de acciones humanas", en CORSO DE ESTRADA, L. E. et al. (eds.), Ley y razón práctica en el pensamiento medieval y renacentista, Pamplona, Eunsa, 2014. 
Miranda Montecinos, Alejandro, El principio del doble efecto, Hildesheim, Georg Olms Verlag, 2014.

Miranda Montecinos, Alejandro, "Eutanasia, suicidio asistido y principio del doble efecto. Réplica al profesor Rodolfo Figueroa", Rev. Méd. Chile, vol. 140, núm. 2, 2012.

Molina FERnÁndez, Fernando, Estado de necesidad y justificación penal: ¿es lícita la tortura en situaciones extremas?, Colombia, Grupo Editorial Ibáñez, 2009.

NÁQuira, Jaime, Derecho penal. Teoría del delito I, Santiago, McGrawHill, 1998.

Novoa Monreal, Eduardo, Curso de derecho penal chileno. Parte general, 3a. ed., Santiago, Editorial Jurídica de Chile, 2005, t. I.

Nozick, Robert, Anarchy, State and Utopia, New York, Basic Books, 1974.

OHLIN, JD, "Targeting and the Concept of Intent", Michigan Journal of International Law, núm. 35, 2013.

OSSANDón Widow, María Magdalena, "Aborto y justificación”, Revista Chilena de Derecho, vol. 39, núm. 2, 2012, disponible en: http://www.scielo.cl/scielo.php?pid=S0718-34372012000 200006\&script=sci_arttext.

OSSANDón Widow, María Magdalena, "Regulación penal del aborto consentido y dignidad humana”, en AguirrezÁBAL, M. y BERTElsen, S. (eds.), El aborto. Perspectiva filosófica, jurídica y médica. Cuadernos de extensión jurídica 27, Santiago, Universidad de los Andes, 2015.

OXMAN, Nicolás, "Una aproximación al sistema de imputación subjetiva en el derecho penal anglosajón", Revista Ius et Praxis, año 19, núm. 1, 2013, disponible en: http://www.scielo.cl/pdf/iu setp/v19n1/art05.pdf.

Politoff Lifschitz, Sergio y OrTiz Quiroga, Luis, Texto y comentario del Código Penal chileno, Santiago, Editorial Jurídica de Chile, 2002, t. I.

RAGUÉs I VALLÈs, Ramón, “Consideraciones sobre la prueba del dolo”, Revista de Estudios de la Justicia, núm. 4, 2004, disponible 
en: http://web.derecho.uchile.cl/cej/recej/recej4/archivos/ PRUEBA\%20DEL\%20DOLO\%20RAGUES\%20_8_.pdf.

SÁNCHEZ-Ostiz, Pablo, "Principios y reglas como base para un modelo argumentativo intercultural de derecho penal”, en SÁNCHEz-Ostiz, P. (coord.), Multiculturalismo y derecho penal, Pamplona, Thomson Reuters-Aranzadi, 2012.

SÁnchez-Ostiz, Pablo, Fundamentos de política criminal. Un retorno a los principios, Madrid, Marcial Pons, 2012.

Silva SÁnchez, Jesús María, "Asesinatos selectivos en la «guerra punitiva» contra el terrorismo", InDret, núm. 1, 2017.

SiLva SÁnchez, Jesús María, "Los documentos de instrucciones previas de los pacientes (artículo 11.1, Ley 41/2002) en el contexto del debate sobre la (in)disponibilidad de la vida", La Ley. Revista Jurídica Española de Doctrina, Jurisprudencia y Legislación, 2003.

Silva SÁnchez, Jesús María, Aproximación al derecho penal contemporáneo, Barcelona, Bosch, 1992.

Singer, Peter, Ética práctica, Akal, Madrid-España, 2009.

VARGas PInTo, Tatiana, “ ¿Tiene la necesidad cara de hereje? Necesidad justificante y exculpante del artículo 10, número 11", en VAN WeEzel, A. (ed.), Humanizar y renovar el derecho penal. Estudios en memoria de Enrique Cury, Santiago, LegalPublishing, 2013.

Wilenmann Von BeRnath, Javier, "Imponderabilidad de la vida humana y situaciones trágicas de necesidad", InDret, núm. 1, 2016.

Wilenmann, Javier, "El fundamento del estado de necesidad justificante en el derecho penal chileno. Al mismo tiempo, introducción al problema de la dogmática del estado de necesidad en Chile", Revista de Derecho (Valdivia), vol. XXVII, núm. 1, 2014, disponible en: http://mingaonline.uach.cl/pdf/revi der/v27n1/art10.pdf.

ZÚÑIgA FAJURI, Alejandra, "Derechos del paciente y eutanasia en Chile", Revista de Derecho, vol. XXI, núm. 2, 2008, disponible en: http://www.scielo.cl/pdf/revider/v21n2/art05.pdf. 